\title{
PENERAPAN METODE NEWEY WEST DALAM MENGOREKSI STANDARD ERROR KETIKA TERJADI HETEROSKEDASTISITAS DAN AUTOKORELASI PADA ANALISIS REGRESI
}

\author{
Zakiah Nurlaila $^{1 \S}$, Made Susilawati ${ }^{2}$, Desak Putu Eka Nilakusmawati ${ }^{3}$ \\ ${ }^{1}$ Jurusan Matematika, Fakultas MIPA - Universitas Udayana [Email: zakiah1219@gmail.com] \\ ${ }^{2}$ Jurusan Matematika, Fakultas MIPA - Universitas Udayana [Email: susilawati.made@gmail.com] \\ ${ }^{3}$ Jurusan Matematika, Fakultas MIPA - Universitas Udayana [Email: nilakusmawati@unud.ac.id] \\ ${ }^{\S}$ Corresponding Author
}

\begin{abstract}
Ordinary Least Squares (OLS) used to estimate the parameters in the regression analysis. If one of the assumptions is not fulfilled, the results of the OLS are no longer best, linear, and unbiased properties. The aim of this research was to find out the application of Newey West method to correct standard error when heteroscedasticity and autocorrelation occurred, and to compare the results of OLS with Newey West method on secondary and simulation data. OLS can still be used to estimate the regression parameter when heteroscedasticity and autocorrelation occurred. However, it will cause bias on standard error of parameter. A method which can correct the standard error of parameters to be unbiased parameter is Newey West method. The secondary data about Passenger Car Milage and data simulated contain heteroscedasticity and autocorrelation. The analysis showed that the Newey West method were known is able to correct standard error when heteroscedasticity and autocorrelation occurred on both of data. It was obtained that Newey west method with $g=3$ and $g=4$ changes the value of the bias standard error of OLS to be unbiased.
\end{abstract}

Keywords: Autocorrelation, Heteroscedasticity, Newey West Method, Ordinary Least Square

\section{PENDAHULUAN}

Metode Kuadrat Terkecil atau sering disebut dengan metode Ordinary Least Square (OLS) merupakan salah satu metode yang dapat digunakan untuk mengestimasi parameter dalam analisis regresi. Prinsip dari OLS adalah meminimumkan jumlah kuadrat error (Neter et $a l$, 1997). Namun, terdapat beberapa asumsi pada analisis regresi yang harus dipenuhi dalam melakukan estimasi dengan OLS. Asumsi tersebut adalah data harus mengikuti sebaran normal, homoskedastisitas, tidak ada multikolinearitas, dan tidak ada autokorelasi. Apabila semua asumsi terpenuhi maka hasil estimasi dengan OLS dikatakan memenuhi sifat Best Linear Unbiased Estimator (BLUE).

Pelanggaran asumsi yang sering terjadi pada analisis regresi adalah terjadinya heteroskedastisitas dan autokorelasi. Heteroskedastisitas terjadi ketika varian dari error model regresi tidak konstan, sedangkan autokorelasi terjadi ketika adanya korelasi antara satu error dengan error yang lain (Widarjono, 2007).

Wooldridge (2009) menjelaskan bahwa keberadaan heteroskedastisitas dan autokorelasi dalam model regresi tidak memengaruhi sifat tak bias dan konsistensi dari parameter regresi pada OLS. Akan tetapi, standard error dari parameter yang diperoleh menjadi bias, varian lebih kecil atau lebih besar, dan berakibat uji $t$ dan uji $F$ menjadi tidak valid. Sehingga dapat berakibat kesimpulan yang ditarik akan salah, karena tidak menggambarkan keadaan yang sebenarnya. Akibat dari keberadaan heteroskedastisitas dan autokorelasi dalam model regresi menyebabkan estimator OLS tidak lagi menghasilkan estimator yang BLUE.

Melihat akibat yang dapat ditimbulkan oleh heteroskedastisitas dan autokorelasi maka 
diperlukan metode alternatif lain dalam estimasi parameter yang dapat mengatasi masalah tersebut, yaitu dengan menggunakan metode Newey West. Metode ini diperkenalkan oleh Newey dan West (1987) sebagai pengembangan dari metode standard error White yang dirancang hanya untuk mengoreksi heteroskedastisitas (Wooldridge, 2009). Penggunaan metode Newey West adalah untuk memperbaiki kesalahan standard error OLS dengan mengoreksi standard error bukan hanya pada permasalahan heteroskedastisitas melainkan juga pada permasalahan autokorelasi.

Gujarati (2004) merekomendasikan penggunaan metode Newey West pada penelitian yang memiliki data dengan jumlah yang cukup besar. Dalam perhitungannya, metode ini tidak membuat model menjadi tidak lagi mengandung heteroskedastisitas dan autokorelasi, namun tetap dapat melakukan pengujian hipotesis yang didasarkan pada distribusi $t$ maupun $F$. Penelitian sebelumnya telah dilakukan oleh Rachmawati dan Sumarminingsih (2014) mengkaji metode Newey West untuk mengatasi heteroskedastisitas dan autokorelasi pada analisis regresi linear berganda. Mereka menunjukkan standard error Newey West yang didapatkan dengan tiga macam nilai $g$ (jumlah lag), yaitu $g=12, g=3$, dan $g=1$ selalu lebih besar nilainya dari standard error pada OLS.

Penelitian ini bertujuan untuk mengetahui penerapan metode Newey West dalam mengoreksi standard error ketika terjadi heteroskedastisitas dan autokorelasi pada analisis regresi serta mengetahui perbandingan hasil analisis metode OLS dengan Newey West pada data sekunder dan data simulasi.

Regresi yang hanya melibatkan satu variabel respon dan satu variabel bebas disebut dengan analisis regresi linear sederhana, sedangkan regresi yang menghubungkan satu variabel respon dengan dua atau lebih variabel bebas disebut dengan analisis regresi linear berganda. Bentuk umum model regresi linear berganda adalah seperti pada persamaan berikut (Kutner et al, 2004):

$Y_{i}=\beta_{0}+\beta_{1} X_{i 1}+\beta_{2} X_{i 2}+\cdots+\beta_{k} X_{i k}+\varepsilon_{i}$

Pendugaan OLS pada keberadaan heteroskedastisitas atau ketika ragam tidak homogen yang dilambangkan dengan $\operatorname{var}\left(\varepsilon_{i} \mid X_{i}\right)=\sigma_{i}^{2}, \quad$ Wooldridge $\quad$ (2009) menyatakan rumus bagi ragam adalah sebagai berikut:

$$
\operatorname{var}\left(\hat{\beta}_{1}\right)=\frac{\left(\sum_{i=1}^{n}\left(X_{i}-\bar{X}\right)\right)^{2} \sigma_{i}{ }^{2}}{\left(\sum_{i=1}^{n} x_{i}\right)^{2}}
$$

Pendugaan OLS pada keberadaan autokorelasi yang dilambangkan dengan $E\left(u_{i}, u_{j}\right) \neq 0$ untuk $i \neq j$, ditetapkan rumus ragam sebagai berikut (Wooldridge, 2009):

$$
\begin{aligned}
\operatorname{var}\left(\hat{\beta}_{1}\right)= & \frac{\sigma^{2}}{\sum_{t=1}^{n} x_{t}{ }^{2}}+2\left(\frac{\sigma^{2}}{\left(\sum_{t=1}^{n} x_{t}{ }^{2}\right)^{2}}\right) \\
& \sum_{t=1}^{n-1} \sum_{s=1}^{n-1} \rho^{s} X_{t} X_{t-s}
\end{aligned}
$$

Gujarati (2004) menjelaskan bahwa terdapat metode yang tetap dapat mengaplikasikan estimasi OLS dengan model regresi yang tetap sama, namun melakukan koreksi terhadap standard error, yaitu metode standard error Heteroscedasticity and Autocorrelation Consistent (HAC) atau Newey West. Metode Newey West digunakan pada penelitian yang memiliki data dengan jumlah yang cukup besar. Berikut merupakan langkahlangkah metode Newey West (Wooldridge, 2009):

Langkah 1. Sebagai ilustrasi pertimbangkan model regresi linear berganda berikut:

$$
Y_{t}=\beta_{0}+\beta_{1} X_{1 t}+\cdots+\beta_{p} X_{p t}+u_{t}
$$

Menduga parameter regresi $\left(\beta_{0}, \beta_{1}, \ldots, \beta_{p}\right)$ dengan OLS, dan mendapatkan $\operatorname{se}\left(\hat{\beta}_{p}\right), \hat{\sigma}$, dan galat $\operatorname{OLS}\left\{\hat{u}_{t}: t=1,2, \ldots, n\right\}$.

Langkah 2. Melakukan regresi penyokong (auxilliary regression), regresi antara $X_{p}$ dengan peubah bebas lainnya. Misalkan antara $X_{1}$ dengan $X_{2}, X_{3}, \ldots, X_{p}$ untuk mencari $\operatorname{se}\left(\hat{\beta}_{1}\right)$ 


$$
X_{1}=\alpha_{0}+\alpha_{2} X_{2}+\cdots+\alpha_{p} X_{p}+r_{t}
$$

dengan galat $r_{t}$ memiliki rata-rata nol dan tidak berkorelasi dengan $X_{2}, X_{3}, \ldots, X_{p}$. Kemudian, membentuk $\hat{a}_{t}=\hat{r}_{t} \hat{u}_{t}$ (untuk setiap $t$ ).

Langkah 3. Memilih bilangan asli $g$, dan kemudian menghitung nilai $\hat{v}$ dengan rumus sebagai berikut:

$$
\begin{aligned}
& \hat{v}=\sum_{t=1}^{n} \hat{a}_{t}{ }^{2}+2 \sum_{h=1}^{g}\left[1-\frac{h}{(g+1)}\right]\left(\sum_{t=h+1}^{n} \hat{a}_{t} \hat{a}_{t-h}\right)(6) \\
& \text { dengan } \hat{a}_{t}=\hat{r}_{t} \hat{u}_{t}, t=1,2, \ldots, n
\end{aligned}
$$

Langkah 4. Menghitung standard error untuk $\beta_{p}$ yang dikoreksi dengan rumus:

$$
\operatorname{se}_{\text {newey-west }}\left(\hat{\beta}_{p}\right)=\left(\frac{\operatorname{se}\left(\widehat{\beta}_{p}\right)}{\widehat{\sigma}}\right)^{2} \sqrt{\hat{v}}
$$

dengan:

$\operatorname{se}\left(\hat{\beta}_{p}\right)=$ standard error dari regresi awal (4)

$\hat{\sigma}=$ estimator varian model regresi awal (4)

Menurut Wooldridge (2009) nilai $g$ yang digunakan dapat disesuaikan dengan data. Untuk data tahunan dipilih $g=1$ atau $g=2$, data kuartalan $g=4$ atau $g=8$, sementara itu untuk data bulanan dipilih $g=12$ atau $g=24$, serta pada beberapa software seperti STATA dan EViews nilai $g$ yang digunakan adalah $g=\sqrt[4]{n}$. Namun Newey West menyarankan nilai $g=4\left(\frac{n}{100}\right)^{\frac{2}{9}}$.

\section{METODE PENELITIAN}

Sumber data pada penelitian ini adalah data sekunder dan data simulasi. Data sekunder diperoleh dari buku yang berjudul "Basic Econometrics" (Gujarati, 2004). Data yang terdapat di dalam buku ini adalah data mengenai Passenger Car Milage dengan jumlah pengamatan sebanyak 81 buah pengamatan. Variabel respon $(Y)$ yang digunakan adalah Avarage Miles per Gallon (MPG), kemudian variabel bebasnya adalah Top Speed (SP) untuk $\left(X_{1}\right)$, Engine Horsepower (HP) untuk $\left(X_{2}\right)$, Cubic Feet of Coupe Space (VOL) untuk $\left(X_{3}\right)$, dan Vehicle
Weight (WT) untuk $\left(X_{4}\right)$. Sedangkan data simulasi diperoleh dengan membangkitkan data yang mengandung heteroskedastisitas dan autokorelasi sebanyak 100 data menggunakan program R i386 3.0.2. Variabel yang digunakan adalah satu variabel respon $(Y)$ dan empat variabel bebas $(X)$.

Metode analisis data yang digunakan dalam penelitian ini adalah sebagai berikut:

Langkah 1. Melakukan analisis pada data sekunder dan data simulasi dengan tahapan sebagai berikut:

1) Membuat model analisis regresi dengan menggunakan OLS.

2) Melakukan pengujian asumsi klasik untuk melihat apakah hasil estimasi dengan OLS memenuhi asumsi-asumsi dalam analisis regresi.

3) Bila terdapat heteroskedastisitas dan autokorelasi, maka akan dilakukan koreksi standard error menggunakan metode Newey West, dengan langkah sebagai berikut:

a. Menghitung nilai $\hat{v}$ dalam metode Newey West dengan $g=\sqrt[4]{n}$ dan

$$
g=4\left(\frac{n}{100}\right)^{\frac{2}{9}} \text {. }
$$

b. Menghitung nilai standard error Newey West.

4) Membandingkan nilai standard error yang dihasilkan pada OLS dengan nilai standard error pada metode Newey West.

Langkah 2. Membandingkan hasil analisis metode OLS dengan metode Newey West pada data sekunder dan data simulasi berdasarkan nilai standard error, uji $t$, dan $R^{2}$ yang diperoleh.

\section{HASIL DAN PEMBAHASAN}

\section{Simulasi Data}

Simulasi data dilakukan dengan membangkitkan nilai sisaan atau error $(\varepsilon)$ pada pola linear dan menggunakan model autoregresif tingkat satu (first-order autoregressive), sehingga membentuk data regresi linear berganda yang bersifat 
heteroskedastisitas dan autokorelasi. Ringkasan hasil pembangkitan data dengan $\alpha$ sebesar 0,05 , dapat dilihat pada Tabel 1.

Tabel 1. Ringkasan Hasil Pembangkitan Data

\begin{tabular}{|c|c|c|c|}
\hline \multirow{3}{*}{$n$} & \multirow{2}{*}{ Ulangan } & \multicolumn{2}{|c|}{ Output } \\
\cline { 2 - 4 } & & Heteroskedastisitas & Autokorelasi \\
\hline \multirow{4}{*}{100} & 1 & Tolak $H_{0}$ & Tolak $H_{0}$ \\
\cline { 2 - 4 } & $\vdots$ & $\vdots$ & $\vdots$ \\
\cline { 2 - 4 } & 5 & Tolak $H_{0}$ & Tolak $H_{0}$ \\
\hline \multirow{4}{*}{200} & 1 & Tolak $H_{0}$ & Tolak $H_{0}$ \\
\cline { 2 - 4 } & $\vdots$ & $\vdots$ & $\vdots$ \\
\cline { 2 - 4 } & 5 & Tolak $H_{0}$ & Tolak $H_{0}$ \\
\hline \multirow{3}{*}{500} & 1 & Tolak $H_{0}$ & Tolak $H_{0}$ \\
\cline { 2 - 4 } & $\vdots$ & $\vdots$ & $\vdots$ \\
\cline { 2 - 4 } & 5 & Tolak $H_{0}$ & Tolak $H_{0}$ \\
\hline \multirow{3}{*}{1.000} & 1 & Tolak $H_{0}$ & Tolak $H_{0}$ \\
\cline { 2 - 4 } & $\vdots$ & $\vdots$ & $\vdots$ \\
\cline { 2 - 4 } & 5 & Tolak $H_{0}$ & Tolak $H_{0}$ \\
\hline
\end{tabular}

Berdasarkan Tabel 1 ringkasan hasil pembangkitan data yang dilakukan pada jumlah data $(n)$ sebanyak 100, 200, 500, dan 1.000 data, menghasilkan keputusan yang sama pada masing-masing ulangan satu hingga lima di setiap jumlah data yang telah ditentukan. Sebagai hasil diperoleh bahwa baik untuk pengujian adanya unsur heteroskedastisitas dan autokorelasi, $H_{0}$ ditolak. Hal ini berarti terdapat gejala heteroskedastisitas dan autokorelasi pada data yang telah dibangkitkan.

\section{Estimasi dengan OLS}

Model estimasi untuk data Passenger Car Milage dengan OLS adalah

$$
\begin{aligned}
\widehat{M P G}_{i}= & 188,70-1,25 S P_{i}+0,38 H P_{i}- \\
& 0,01 V O L_{i}-1,86 W T_{i}
\end{aligned}
$$

dengan koefisien determinasi $R^{2}$ sebesar 0,88 . Berdasarkan nilai $R^{2}$ tersebut mengindikasikan bahwa variabel-variabel bebas menjelaskan variabel respon (MPG) sebesar 88\%. Sedangkan model estimasi dengan OLS untuk data simulasi adalah sebagai berikut:

$$
\begin{gathered}
\widehat{Y}_{i}=65,71+28,18 X_{i 1}+97,35 X_{i 2}+95,53 X_{i 3}+ \\
47,05 X_{i 4}
\end{gathered}
$$

dengan koefisien determinasi $R^{2}$ sebesar 0,99. Berdasarkan nilai $R^{2}$ tersebut mengindikasikan bahwa variabel-variabel bebas menjelaskan variabel respon sebesar 99\%. Namun untuk mengetahui bahwa hasil estimasi tersebut mengandung heteroskedastisitas dan autokorelasi atau tidak maka selanjutnya dilakukan pengujian asumsi klasik terhadap asumsi homoskedastisitas dan asumsi tidak adanya autokorelasi. Selain itu, juga dilakukan pengujian terhadap asumsi kenormalan dan tidak adanya multikolinearitas. Jika salah satu asumsi tidak terpenuhi, maka hasil estimasi dengan OLS tidak efisien untuk digunakan.

\section{Pengujian Asumsi Klasik}

Hasil yang diperoleh dari pengujian terhadap asumsi kenormalan baik untuk data Passenger Car Milage maupun data simulasi adalah error tidak mengikuti sebaran normal dengan nilai $\mathrm{P}$-value masing-masing sebesar 0,011 dan 0,005 yang lebih kecil dari $\alpha$ sebesar 0,05 . Kemudian untuk hasil dari pengujian terhadap asumsi homoskedastisitas adalah model regresi mengandung heteroskedastisitas dengan nilai P-value kedua data sebesar 0,000 yang lebih kecil dari $\alpha$. Selain itu, plot antara error yang terstandarisiasi dengan nilai dugaannya juga mengindikasikan adanya heteroskedastisitas, dengan plot yang dihasilkan pada data Passenger Car Milage menunjukkan pola sebaran yang meningkat yaitu secara terus-menerus bergerak menjauhi nol dan pada data simulasi, pola sebaran sistematis menunjukkan titik-titik yang bergerak mendekati nol.

Selanjutnya hasil yang diperoleh dari pengujian terhadap asumsi tidak adanya autokorelasi adalah model regresi mengandung autokorelasi dengan nilai P-value data Passenger Car Milage sebesar 0,0004 dan data simulasi sebesar 0,0000 yang lebih kecil dari $\alpha$. Kemudian untuk hasil dari pengujian terhadap asumsi tidak adanya multikolinearitas adalah model regresi mengandung multikolinearitas untuk data Passenger Car Milage dengan nilai VIF variabel SP $\left(X_{1}\right)$ sebesar 71,95917, 
variabel HP $\left(X_{2}\right)$ sebesar 130,0527, VOL $\left(X_{3}\right)$ sebesar 1,559571, dan variabel WT $\left(X_{4}\right)$ sebesar 18,19867 menunjukkan tidak semua variabel bebas memiliki nilai VIF lebih kecil dari 5. Sedangkan untuk data simulasi nilai VIF yang diperoleh untuk variabel $X_{1}$ sebesar 1,017115 , variabel $X_{2}$ sebesar 1,014807, variabel $X_{3}$ sebesar 1,019261, dan variabel $X_{4}$ sebesar 1,019182. Tampak bahwa seluruh variabel bebas memiliki nilai VIF lebih kecil dari 5. Dengan demikian, tidak terdapat variabel yang mengalami multikolinearitas dalam model regresi pada data simulasi.

Berdasarkan hasil pengujian asumsi klasik terjadi heteroskedastisitas dan autokorelasi baik pada data Passenger Car Milage maupun data simulasi, maka dilakukan koreksi standard error menggunakan metode Newey West.

\section{Koreksi Standard Error dengan Metode Newey West}

Koreksi standard error parameter regresi menggunakan metode Newey West pada data Passenger Car Milage dilakukan dengan nilai $g=\sqrt[4]{n}=\sqrt[4]{81}=3$ dan

$g=4\left(\frac{n}{100}\right)^{\frac{2}{9}}=4\left(\frac{81}{100}\right)^{\frac{2}{9}}=4$.

Tabel 2. Pendugaan Parameter dan Pengujian Data Passenger Car Milage dengan Standard Error Newey West $g=3$

\begin{tabular}{crrrrr}
\hline \hline Parameter & Nilai Duga Std. Error & \multicolumn{3}{c}{ t-statistik P-value } \\
\hline \hline$\beta_{0}$ & 188,7035 & 41,12246 & 4,588819 & 0,0000 \\
$\beta_{1}$ & $-1,252821$ & 0,405465 & $-3,089841$ & 0,0028 \\
$\beta_{2}$ & 0,380581 & 0,133382 & 2,853310 & 0,0056 \\
$\beta_{3}$ & $-0,012113$ & 0,030948 & $-0,391393$ & 0,6966 \\
$\beta_{4}$ & $-1,855283$ & 0,368710 & $-5,031820$ & 0,0000 \\
\hline \hline
\end{tabular}

Berdasarkan Tabel 2 diperoleh bahwa nilai duga untuk tiap parameter regresi tidak berubah atau tetap sama seperti pada hasil pengujian menggunakan OLS. Pada hasil tersebut juga ditunjukkan bahwa nilai P-value parameter regresi $\beta_{0}$ dan $\beta_{4}$ sebesar $0,0000, \beta_{1}$ sebesar 0,0028 , serta $\beta_{2}$ sebesar 0,0056 . Sehingga parameter-parameter regresi yang diperoleh signifikan pada $\alpha$ sebesar 0,05 , sedangkan parameter $\beta_{3}$ tidak signifikan karena nilai $\mathrm{P}$ value yang diperoleh lebih besar dari $\alpha(0,6966>0,05)$.

Tabel 3. Pendugaan Parameter dan Pengujian Data Passenger Car Milage dengan Standard Error Newey West $g=4$

\begin{tabular}{ccccc}
\hline \hline Parameter & \multicolumn{2}{c}{ Nilai Duga Std. Error } & \multicolumn{3}{c}{ t-statistik P-value } \\
\hline \hline$\beta_{0}$ & 188,7035 & 41,62620 & 4,533287 & 0,0000 \\
$\beta_{1}$ & $-1,252821$ & 0,410131 & $-3,054684$ & 0,0031 \\
$\beta_{2}$ & 0,380581 & 0,136152 & 2,795270 & 0,0066 \\
$\beta_{3}$ & $-0,012113$ & 0,032123 & $-0,377068$ & 0,7072 \\
$\beta_{4}$ & $-1,855283$ & 0,382852 & $-4,845956$ & 0,0000 \\
\hline \hline
\end{tabular}

Pada Tabel 3 ditunjukkan bahwa nilai Pvalue parameter regresi $\beta_{0}$ dan $\beta_{4}$ sebesar $0,0000, \beta_{1}$ sebesar 0,0031 , serta $\beta_{2}$ sebesar 0,0066 . Sehingga parameter-parameter regresi yang diperoleh signifikan pada $\alpha$ sebesar 0,05 , sedangkan parameter $\beta_{3}$ tidak signifikan karena nilai P-value yang diperoleh lebih besar dari $\alpha(0,7072>0,05)$. Hasil dari pengujian data Passenger Car Milage menggunakan OLS dengan metode Newey West menghasilkan pengambilan keputusan yang sama meski dengan nilai standard error, uji $t$, dan signifikansi yang berbeda.

Kemudian, koreksi standard error parameter regresi menggunakan metode Newey West pada data simulasi dengan nilai $g=$ $\sqrt[4]{n}=\sqrt[4]{100}=3$ dan

$g=4\left(\frac{n}{100}\right)^{\frac{2}{9}}=4\left(\frac{100}{100}\right)^{\frac{2}{9}}=4$.

Tabel 4. Pendugaan Parameter dan Pengujian Data Simulasi dengan Standard Error Newey West $g=3$

\begin{tabular}{|c|c|c|c|c|}
\hline Parameter & Nilai Duga & Std. Error & t-statistik & -value \\
\hline$\beta_{0}$ & 65,70928 & 1,678142 & 39,15597 & 0,0000 \\
\hline$\beta_{1}$ & 28,18535 & 0,050074 & 562,8783 & 0,0000 \\
\hline$\beta_{2}$ & 97,35269 & 0,007486 & 13005,07 & 0,0000 \\
\hline$\beta_{3}$ & 95,53171 & 0,021509 & 4441,454 & 0,0000 \\
\hline$\beta_{4}$ & 47,05470 & 0,008236 & 5713,108 & 0,0000 \\
\hline
\end{tabular}


Tabel 5. Pendugaan Parameter dan Pengujian Data Simulasi dengan Standard Error Newey West $g=4$

\begin{tabular}{ccccc}
\hline \hline Parameter & \multicolumn{3}{c}{ Nilai Duga Std. Error } & \multicolumn{3}{c}{ t-statistik P-value } \\
\hline \hline$\beta_{0}$ & 65,70928 & 1,697829 & 38,70195 & 0,0000 \\
$\beta_{1}$ & 28,18535 & 0,050477 & 558,3826 & 0,0000 \\
$\beta_{2}$ & 97,35269 & 0,007185 & 13549,89 & 0,0000 \\
$\beta_{3}$ & 95,53171 & 0,022044 & 4333,681 & 0,0000 \\
$\beta_{4}$ & 47,05470 & 0,008196 & 5740,912 & 0,0000 \\
\hline \hline
\end{tabular}

Pada Tabel 4 dan Tabel 5 ditunjukkan bahwa nilai $\mathrm{P}$-value pada parameter regresi $\beta_{0}, \beta_{1}, \beta_{2}, \beta_{3}$, dan $\beta_{4}$ sebesar 0,0000 . Sehingga parameter-parameter regresi yang diperoleh signifikan pada $\alpha$ sebesar 0,05 . Hasil dari pengujian data simulasi menggunakan OLS dengan metode Newey West menghasilkan pengambilan keputusan yang sama meski dengan nilai standard error dan uji $t$ yang berbeda.

\section{Perbandingan Nilai Standard Error OLS dengan Metode Newey West}

Berikut disajikan tabel perbandingan nilai standard error ketika menggunakan OLS dengan metode Newey West pada data Passenger Car Milage.

Tabel 6. Perbandingan Nilai Standard Error OLS dengan Newey West pada Data Passenger Car Milage

\begin{tabular}{|c|c|c|c|}
\hline \multirow{2}{*}{ Parameter } & \multicolumn{3}{|c|}{ Standard Error } \\
\cline { 2 - 4 } & $\begin{array}{c}\text { OLS pada } \\
\text { Data Asli }\end{array}$ & $\begin{array}{c}\text { Newey } \\
\text { West } \\
\boldsymbol{g = 3}\end{array}$ & $\begin{array}{c}\text { Newey } \\
\text { West } \\
\boldsymbol{g = 4}\end{array}$ \\
\hline$\beta_{0}$ & 22,74704 & 41,12246 & 41,62620 \\
\hline$\beta_{1}$ & 0,236692 & 0,405465 & 0,410131 \\
\hline$\beta_{2}$ & 0,078668 & 0,133382 & 0,136152 \\
\hline$\beta_{3}$ & 0,022062 & 0,030948 & 0,032123 \\
\hline$\beta_{4}$ & 0,205843 & 0,368710 & 0,382852 \\
\hline
\end{tabular}

Nilai standard error OLS data asli pada Tabel 6 terlihat bahwa nilai standard error tersebut masih belum menunjukkan nilai yang sesungguhnya sebab data terindikasi heteroskedastisitas dan autokorelasi. Setelah dilakukan koreksi menggunakan metode Newey West, terjadi perubahan nilai standard error baik pada nilai $g=3$ dan $g=4$.
Perubahan yang terjadi untuk setiap parameter regresi selalu lebih besar dari nilai standard error OLS. Hasil penanganan yang telah diperoleh memberikan arti memperbaiki standard error dari model regresi yang memuat heteroskedastisitas dan autokorelasi. Kata memperbaiki di sini tidak memberikan arti memperkecil standard error dari model yang diestimasi dengan OLS, namun memberikan nilai standard error yang sebenarnya dari model yang memuat heteroskedastisitas dan autokorelasi.

Lebih lanjut lagi, disajikan tabel perbandingan nilai standard error ketika menggunakan OLS dengan metode Newey West pada data simulasi.

Tabel 7. Perbandingan Nilai Standard Error OLS dengan Newey West pada Data Simulasi

\begin{tabular}{|c|c|c|c|}
\hline \multirow{4}{*}{ Parameter } & \multicolumn{3}{|c|}{ Standard Error } \\
\cline { 2 - 4 } & $\begin{array}{c}\text { OLS pada } \\
\text { Data } \\
\text { Simulasi }\end{array}$ & $\begin{array}{c}\text { Newey } \\
\text { West } \\
\boldsymbol{g}=\mathbf{4}\end{array}$ & $\begin{array}{c}\text { Newey } \\
\text { West } \\
\boldsymbol{g}=\mathbf{3}\end{array}$ \\
\hline$\beta_{0}$ & 0,698844 & 1,678142 & 1,697829 \\
\hline$\beta_{1}$ & 0,020040 & 0,050074 & 0,050477 \\
\hline$\beta_{2}$ & 0,020428 & 0,007486 & 0,007185 \\
\hline$\beta_{3}$ & 0,015041 & 0,021509 & 0,022044 \\
\hline$\beta_{4}$ & 0,015628 & 0,008236 & 0,008196 \\
\hline
\end{tabular}

Tabel 7 ditunjukkan bahwa terdapat perubahan nilai standard error yang dihasilkan metode Newey West baik pada nilai $g=3$ dan $g=4$. Perubahan yang terjadi untuk setiap parameter regresi tidak selalu lebih besar dari nilai standard error OLS. Hasil penanganan yang telah diperoleh menunjukkan bahwa nilai standard error OLS yang bias menjadi tak bias setelah diterapkannya metode Newey West.

\section{Perbandingan Hasil Analisis Metode OLS dengan Metode Newey West pada Data Passenger Car Milage dan Data Simulasi}

Analisis data Passenger Car Milage dan data simulasi menggunakan metode OLS diperoleh bahwa nilai standard error yang dihasilkan belum menunjukkan nilai yang sebenarnya, sebab masih terindikasi heteroskedastisitas dan autokorelasi. Setelah 
dikoreksi menggunakan metode Newey West, terjadi perubahan pada nilai standard error dari masing-masing parameter regresi baik pada data Passenger Car Milage dan data simulasi dengan nilai $g=3$ maupun $g=4$. Sehingga nilai standard error dari parameter yang awalnya bias telah berubah menjadi tidak bias. Dengan demikian uji $t$ dan uji $F$ menjadi valid serta dapat ditarik kesimpulan yang tepat, karena telah menggambarkan keadaan yang sebenarnya.

Perubahan nilai standard error dari parameter diikuti oleh perubahan nilai uji $t$ dan nilai signifikansinya. Namun perubahan yang terjadi pada nilai uji $t$ dan nilai signifikansi ini tidak terlalu besar, sehingga keputusan yang diambil tetap sama ketika menggunakan metode OLS maupun metode Newey West. Hasil uji $t$ pada data Passenger Car Milage diperoleh bahwa tidak semua variabel bebas berpengaruh secara parsial terhadap variabel respon. Variabel bebas yang berpengaruh yaitu kecepatan tertinggi dalam mil/jam $\left(X_{1}\right)$, daya mesin $\left(X_{2}\right)$, dan berat kendaraan dalam ratusan pon $\left(X_{4}\right)$, sedangkan untuk variabel bebas volume ruang kabin $\left(X_{3}\right)$ tidak berpengaruh secara parsial terhadap rata-rata jarak per satuan bahan bakar $(Y)$. Kemudian, pada data simulasi diperoleh hasil uji $t$ bahwa seluruh variabel bebas dalam model regresi yaitu $X_{1}, X_{2}, X_{3}$, dan $X_{4}$ berpengaruh secara parsial terhadap variabel respon $(Y)$.

Penerapan metode Newey West dalam mengoreksi standard error OLS, tidak mengubah hasil analisis yang lainnya pada metode OLS selain nilai standard error yang diikuti oleh perubahan nilai uji $t$ dan nilai signifikansinya. Model estimasi yang digunakan pada metode OLS dan metode Newey West tetap sama untuk kedua data dalam penelitian ini. Nilai koefisien determinasi ganda $\left(R^{2}\right)$ merupakan salah satu hasil analisis yang tidak berubah. Pada data Passenger Car Milage diperoleh nilai $R^{2}$ sebesar $88 \%$ sedangkan pada data simulasi diperoleh nilai $R^{2}$ sebesar $99 \%$.

\section{KESIMPULAN DAN SARAN}

Penerapan metode Newey West mampu mengoreksi standard error ketika terjadi heteroskedastisitas dan autokorelasi dalam analisis regresi baik pada data Passenger Car Milage maupun data simulasi. Hal ini terlihat pada perubahan nilai standard error OLS yang bias menjadi tidak bias setelah dikoreksi menggunakan metode Newey West dengan nilai $g=3$ dan $g=4$ pada kedua data tersebut.

Hasil uji $t$ metode OLS dan metode Newey West pada data Passenger Car Milage menunjukkan bahwa tidak semua variabel bebas dalam model regresi berpengaruh secara parsial terhadap variabel respon, sedangkan pada data simulasi diperoleh bahwa seluruh variabel bebas dalam model regresi yaitu $X_{1}, X_{2}, X_{3}$, dan $X_{4}$ berpengaruh secara parsial terhadap variabel respon $(Y)$. Selain itu, nilai koefisien determinasi ganda $\left(R^{2}\right)$ yang menyatakan variabel-variabel bebas menjelaskan variabel respon dalam model regresi pada data Passenger Car Milage sebesar $88 \%$ sedangkan pada data simulasi sebesar $99 \%$.

Saran yang dapat penulis sampaikan yaitu metode Newey West tidak dapat menghilangkan gejala heteroskedastisitas dan autokorelasi yang terkandung dalam model, namun hanya memparbaiki nilai standard errornya saja. Untuk itu sangat diperlukan suatu metode yang robust untuk mengatasi heteroskedastisitas dan autokorelasi.

\section{DAFTAR PUSTAKA}

Gujarati, N. D. 2004. Basic Econometrics. 4th ed. New York: McGraw-Hill Companies, Incorporation.

Kutner, M. H., Nachtsheim, C. J. \& Neter, J. 2004. Applied Linear Regression Models. 4th ed. New York: McGraw-Hill Companies,Incorporation.https://datamfr.fi les.wordpress.com/2012/10/regresi-linierberganda.pdf. Diakses 5 Maret 2016. 
Neter, J., Wasserman, W. \& Kutner, M. H. 1997. Model Linear Terapan Buku I dan II:Analisis Regresi Linear Sederhana danAnalisis Regresi Ganda. Penerjemah: Bambang Sumantri. Bogor: Jurusan Statistika FMIPA IPB.

Rachmawati, D. S. dan Sumarminingsih, E. 2014. Metode Standard Error Newey West untuk Mengatasi Heteroskedastisitas dan Autokorelasi pada Analisis Regresi Linier Berganda. Vol 2, No. 1, pp. 65-68.

http://statistik.studentjournal.ub.ac.id/inde x.php/statistik/article/view/103. Diakses 17 Februari 2016.
Widarjono, A. 2007. Ekonometrika Teori dan Aplikasi untuk Ekonomi dan Bisnis. Edisi Kedua. Yogyakarta: Ekonisia Fakultas Ekonomi Universitas Islam Indonesia. https://datamfr.files.wordpress.com/2012/1 0/regresi-linier-berganda.pdf. Diakses 5 Maret 2016.

Wooldridge, J. M. 2009. Introductory Econometrics.4thed. Canada: Nelson Education.http://ncbae.yolasite.com/resour ces/IntroductoryEconometrics_AModernA pproach_FourthEdition_Jeffrey_Wooldrid ge.pdf.Diakses 21 Februari 2016. 